\title{
Professional Socio-Anthropology in France: Transferable Knowledge Thanks to the Constraint of the Diversity of Business Demands
}

\author{
Dominique Desjeux \\ University of Paris
}

In the 19th century and until the 1960s, French professional anthropology was mainly used to better understand the functioning of colonial societies. From the 1970s onwards, some anthropologists began to enter into immigrant circles in French cities and in the poorest social classes. Around the 1990s, professional anthropology was extended to the world of business, consumption and innovation. Today, French professional anthropologists conduct surveys on the lifestyles of the poor as well as the most privileged middle classes, in urban and rural areas, in France and abroad, in companies, administrations and NGOs. At the time of conducting a survey, there is no major difference between an academic approach and a professional approach. The difference is that professional anthropology operates mainly on demand and therefore does not choose its fields. This leads the professional anthropologist to acquire great intellectual mobility and not to specialise in a single field, as is often the case in the academic world.

Keywords: ROD, applied socio-anthropology, eating habits, meat consumption

\section{INTRODUCTION}

This article, half observation of the environment and half testimony, starts from an observation: part of the academic world in France has a rather negative image of Anthropology in Business (Denny and Sunderland 2014). I will not start from an investigation as I usually do. I will start from my experience as an academician and my work for companies, administrations or NGOs since 1969; as a sociologist in various organisations; and as an anthropologist of consumption in France and the world (Desjeux 2018) at large.

This reflection is part of a debate that has often been implicit for several years among French sociologists and anthropologists. It can also be found in China, the United States, Brazil and Africataking only a few countries where I could conduct surveys.

It is concerned with the distinction made between so-called fundamental academic research on the one hand and contract research, i.e. ROD (Research on Demand) (Desjeux 2014), also called applied research, on the other hand. The application of the latter may have its function to do with public policies, companies or NGOs, all of which are grouped here under the term "professional" or "business". ROD is concerned with both qualitative sociologists and anthropologists. In France, they are referred to as socio-anthropologists. My objective is to show that this distinction, which is entirely acceptable, nevertheless prevents us from seeing the contributions of ROD to scientific production in the humanities and social sciences, as well as from seeing certain dead ends of "denunciatory" approaches which are 
seen as being critical. If the term "critical" is not limited to denunciation, but encompasses all scientific approaches, it then becomes possible to reassess the possibilities for intellectual cooperation between the fields.

\section{HOW APPLIED SOCIO-ANTHROPOLOGY SHOWS THAT THE "DISCIPLINING" OF SOCIAL ACTORS IS NOT SELF-EVIDENT: HIGHLIGHTING THE MARGINS OF MANOEUVRE OF SOCIAL ACTORS}

In 2019, in the presentation of issue 38 of the French journal Sociologies Pratiques (2018), one of the publishers described socio-anthropology applied to innovation problems as a "utilitarian and normative vision of sociology, as an instrument of social conformation in the face of resistance to change [...] as a tool for disciplining populations", a little equivalent to "dirty work" in concentration camps (Hughes 1962). It is a strong criticism. It is more surprising because of such publication in a journal that involves social sciences and humanities professionals working on request, and by a person who is a sponsor of these requests.

Put simply, fundamental research is considered as noble, pure and free, while applied research is seen as utilitarian and instrumentalised, being under the constraint of the business request that finances it making it less pure and less free. Above all, its main function is to bring the behaviour of employees, the poor or consumers in line with the expectations of the "dominant" groups, the "fat cats", "finance", "capitalism", "the economy", or "the market".

However, this criticism, which is entirely acceptable, when becomes too coherent eliminates all the contradictory elements that might show that this "bringing human behaviour into line with expectations" does not happen automatically. It does not work as well as this denunciation might suggest or as the "dominant" parties would like it to do. Like any "conspiracy theory", it has a portion of truth in it. However, its hyper-coherence, which leaves no room for other less absolute explanations, makes it impossible to falsify. This means that we can no longer distinguish between what is true and what is false.

This generalizing approach simultaneously disqualifies the approaches seeking to solve problems step by step without questioning "the entire system" all at once. Very often, it can be observed that violent revolutions and coups d'état in history, which are carried out in the name of justice, lead to authoritarian and totalitarian regimes. These regimes do not resolve the problem of equality, but allow a new section of the elites to take power (Desjeux 1980). Most often, on the mesosocial scale, we observe that it is the accumulation of incremental changes that produces disruptive effects and changes the system. However, incremental change is one of the bases of the practice of ROD and its progressive search for resolving problems. This does not prevent us from observing that violence and crises are present in all human societies.

The French sociologist Luc Boltanski, one of the most brilliant proponents of a "critical" form of sociology, first denounced the domination of capitalism (Boltanski and Chiapello, 1999). However, 13 years later, he showed the limits of his denunciation and his conspiratorial drift in a new book (Boltanski 2012). Here he shows how explanation with reference to the "spirit of capitalism" creates an overhanging intention that overvalues the causal link between the intention of the "dominant" party, i.e. that of the managerial or marketing discourse in companies, or that of public policies on the part of the State, to the detriment of the observation of the real practices of social actors in certain situations. He also mentions the possibility of using scales of observation to resolve this tension between domination and the interplay of actors (Desjeux 2018, 109-122; Becker 2017). Indeed, most of the research on demand (ROD) I have carried out on actors' interplay shows that the intention to dominate, to involve employees, or to make consumers conform to expectations, should not be confused with the real practices of social actors in the face of this "conspiracy of the dominant parties".

Indeed, empirical socio-anthropological field surveys will often show, at the microsocial and mesosocial scales, the existence of margins of manoeuvre regarding possible intentions to dominate social actors to change them, whether to make them buy a consumer good or a service, or to make them adopt a virtuous behaviour towards sustainable development, as we will see in the example of meat below. All 
surveys show how difficult it is to obtain the behaviour expected of a consumer or citizen. It is generally accepted in the United States and France, although the statistics are sparse and unreliable, that " $80 \%$ " of innovations that are introduced in the market fail (Desjeux 2013). The automatic effect of domination should therefore be put in perspective. It should also not be forgotten that the "dominant" countries are themselves under pressure of international competition for access to raw materials, financial markets, energy, consumers or the control of digital technologies.

The empirical study of organisations, whether they are public or private organisations or associations, shows us that the members of a company are actors having room for manoeuvre and that discipline, i.e. domination, is not self-evident. The idea of "disciplining" is inspired by Michel Foucault's work, especially his book Discipline and Punish (Foucault 1975) in which he presents in particular the panopticon imagined by Benjamin Bentham (Bentham 1780), a system of total control of prisons by one single person.

Like all approaches which take intention as a point of departure, including those which are formulated by the "dominant actors", the approach in terms of "disciplining" underestimates the ability of actors to play with the rules of the game. There is very often an answer of the "weak to the strong" which confuses the established power. Assigning a high status to intention in order to explain actors' problems is the particular feature of the "persecution-based" approaches. They start off with a true fact, in particular an intention, to transform it into a threat, a conspiracy, the coherence of which does not allow any margin of manoeuvre for the individual or the group (Desjeux 2019).

The ability of actors to play with the organised system, in other words to manage power relations and not just to resist against domination, was demonstrated long ago by Gouldner (1955), Goffman (1961) and Crozier (1964). I have observed this in most of the surveys conducted by myself in certain companies, large organisations or associations. We observe both actors' games and burnout; forms of cooperation as well as conflicts; and effects of domination as well as power relations in which the dominated ones are not always the losers. ${ }^{1}$

For my part, I am convinced that there are effects of domination. They are most often observable on the macrosocial scale. They appear in particular when there is strong physical coercion based on the use of weapons (Desjeux 2018, 81-88). Domination can be exercised through technological coercion related to digitisation or the industrial production process. Financial debt can have the same effect. Symbolic, magical-religious coercion, as in the case of "witchcraft" in Congo, where I worked for four years in the 1970s (Desjeux 2018, 97-108), is a powerful means of coercion on individuals. The domination approach is therefore there to remind us of the importance of power relations in social and geopolitical life.

This approach also reminds us that social classes do exist, and that there are new middle classes on a global level (Desjeux 2018, 295-304; 319-330; 343-352). It also shows us that the elites can keep power for themselves, as is shown by an article in The Guardian on the elites, which recalls: "Those who went to private school comprise $7 \%$ of the country's population but $39 \%$ of the elite; those who went to Oxford or Cambridge University comprise less than $1 \%$ of the population but $24 \%$ of the elite" (Younge 2019).

It may be useful to recall here that in anthropology showing a difference does not mean that the other has no value. Just because a large part of my surveys are carried out at microsocial scales, those of the interplay of actors in the family, the workshop or the office, or mesosocial, that of the interplay of actors in large organisations and concrete systems of action, does not mean that the critical approach that denounces the effects of domination is not interesting. It highlights other hidden facets of society at the macrosocial scale, but often without real evidence of the cause-and-effect relationship between the intention to dominate and the effects on social actors.

What should be retained is the importance of the effects of scales of observation in the description of social reality, and therefore in the debates. Showing that there are effects of domination or of social class relates to the description or the denunciation of society. Denunciation of domination often has the effect of liberating oneself, in conspiratorial imagination, from the constraints of everyday life. It has nothing to do with the study of incremental action, which most often makes it necessary to focus on the interplay of actors. 
The concept of domination effectively eliminates power relations, a fundamentally interactionist concept that cuts across all compartments of human life. Power relations, varying according to situations, are indicators of the actors' room for manoeuvre and their ability to organise themselves. They reveal the limits of "submission to authority" (Milgram 1974). They do not eliminate the unequal distribution of assets in society.

Not every social inequality, or every social difference, is an effect of domination, unless we think that there existed an ideal world before the arrival of the State (the symbol of domination) around $3300 \mathrm{BC}$, in Sumer between the Tigris and the Euphrates, a point of view which is brilliantly defended by the "anarchist" current of anthropological history, such as Sahlins (1972), Clastre (1974), Graeber (2015) Scott (2017). This conclusion is difficult to accept if we take the point of view of the Neanderthal man who was physically eliminated by Sapiens existing long before the birth of the State. There is no paradise lost. Everything was not better before (Jerphagnon, 2007). Life is a permanent struggle closer to the myth of Sisyphus than to a stateless society where the law of the strongest prevails.

\section{HIGHLIGHTING POWER RELATIONS RELATIVISES THE ESSENTIALIST VISION OF DOMINATION}

This distinction between a "conspiratorial" analysis of domination and an analysis in terms of power games and room for manoeuvre is another way of presenting the divide between fundamental and applied research. It distinguishes between a form of sociology which denounces - called sociologie critique in France - and a sociology that seeks to understand. However, "comprehension-based sociology" is also critical, as is any scientific approach. It deconstructs the actors' discourse to show the implicit underpinnings of the functioning of society, which are often invisible to the same actors. It shows that there are power relations, differences of interests and therefore that the actors targeted by marketing and management executives are not as passive and easily manipulated as they believe, as the anti-bureaucracy or anti-domination activists believe symmetrically in reverse. "Resistance" against "domination" is not the only mode of social regulation between actors in the same society. There is a place for strategic interplay and negotiations.

It is also possible to show that academic research, which is supposed to be fundamental and free, may be less free than it claims in relation to schools of thought, the relationship of subordination with thesis or research directors, the scarcity of public funding or in relation to one of the strong group norms which is more to analyse society from the "dominant" angle of domination and inequality than from the perspective of truth and the search for problem solving. In this perspective, domination is thought to be true because it is unfair. Injustice may be true, but empirical evidence of its causal link with the intention to dominate often remains unproven.

When comparing field practices, it can be seen that the difference between fundamental and applied empirical research is not always relevant. Is, ultimately, the distinction between fundamental and applied research so fundamental? The process of carrying out a survey, whether for academic purposes or in relation to a request from a company or a local authority, involves many of the same techniques for collecting information and verifying data. The time spent on the survey will often be shorter in applied contract research than in academic research. This does not mean that applied research is less scientific, but, it is because of budget constraints and reduced number of days available that the socio-anthropologist has learnt to work with more productivity. What may vary, after a survey, is the time that will be spent to model and theorise the results obtained. It is greater in fundamental research. The time that will be spent reflecting on the transition to action, on the management of change with the actors involved in the transformation, is greater in applied research. The target aimed at is also different: colleagues for the former, and clients for the latter. In one case theoretical abstraction will be valued, and in another case, it is instead the avenues for collective action, and hence the potential verification of the validity of the results at the moment action is taken.

All the discussion tends to show that it is not the reality of domination which poses a problem, if it is empirically established, but the essentialist conception of domination. Essentialism presupposes an 
explanation or a solution outside any situation, any effect of social construction by the actors, and thus eliminates any contingency in favour of a determinism and coherence that underlie part of the essentialist approaches.

If we accept the limitations of essentialist approaches, this means that private companies are not inherently bad, nor is the State negative in itself and in particular the rule of law based on democratic institutions. Social actors are not inherently dominated. The solutions of those who are dominated are not always applicable for everyone, no more than those of companies would apply to the State. The effects of dominance come from an analysis in situ which makes it possible to display the variability of social constraints as a function of the interplay of actors. Depending on the situation, we find ourselves the dominated or dominant in relation to other actors, at least in a long-term historical perspective. 19th century imperial France and England no longer seem in a position to dominate the world in the 21st century. The United States feels threatened. China and India feel like they are growing wings.

All this shows that the borderline is not only between the academic and professional worlds; between purity and impurity; but also between two conceptions of the uses of anthropology and sociology. One approach seeks to understand, the other seeks to denounce. It is true, however, that the sociology that denounces seems more frequent in the academic world than in the world of professional sociologists who work under contract. The comprehension-based approach therefore competes with a part of traditional academic production which denounces. It can enrich, bypass, or ignore this approach.

This competition with the academic world is likely to increase even more as the number of socio-anthropologists, particularly doctors of anthropology, but also Masters and BAs not working in universities, is increasing sharply throughout the world. This began in the 1990s in the United States and the years 2000/2010 in France, and today in the BRICs, it seems. It will therefore be necessary to be increasingly attentive to what is produced by ROD and in particular what it has to say about the change. The objective is to achieve, if possible, in the long term, a cross-fertilisation between the academic and professional worlds.

\section{THE ELUCIDATION OF CONSTRAINTS IN CHANGE PROCESSES OR HOW TO SHOW THE LIMITS OF THE WILL TO DISCIPLINE BEHAVIOUR IN FAVOUR OF A DECREASE IN MEAT CONSUMPTION IN FRANCE ${ }^{2}$}

As I have just shown, the most conflictual cleavage in France, and probably elsewhere in other countries in various forms, is between denunciation and understanding; precise explanatory boundaries of change between science and politics; right and left; axiological and ethical neutrality are the most blurred. For the comprehension-based approach I am advocating here, change is problematic. The answer is not given in advance, unlike essentialist analyses. It must be explained according to the situations and scales of observation (Desjeux 2018, 109-122).

From this comprehension-based perspective, change can be observed through the processes of innovation that cross companies, public policies or daily life with consumption in the broad sense. It requires the question of who wins or loses from a particular change. This approach elucidates the material, social or cultural constraints ${ }^{3}$ that organise the behaviour of social actors. Understanding the constraints means highlighting the problems to be solved by the actors concerned, whether they are citizens, companies or administrations. There is no presupposition of a final answer, which is why domination may be one of the answers among others depending on social configurations. The term innovation is not reduced here to that of "creativity" or "technological novelty". It covers everything that contributes to producing change in the professional, social or family life of the actors. It is applied in our article to a sustainable development problem focused on the objective of reducing meat consumption. We find the same interplay of constraints when we try to bring about a reduction in energy consumption (Husetowski 2019).

Together with several researchers, we worked on an innovation problem leading to a more economical consumption of meat within the framework of a French public contract from the French National Research Agency (ANR) (Desjeux, Galateau and Barbier 2018). Reducing meat consumption is 
therefore approached here as a process of innovation compared to previous eating habits. Food technology is not new. It is the use that is new. The proposed new practice is in the general interest by seeking to limit $\mathrm{CO} 2$ emissions. But just because change is for the common good does not make it any easier to achieve. As in any innovation process, the transition to a new behaviour is problematic. A change is always under constraint, but a constraint is not always an effect of dominance (Desjeux 2015, $35)$.

The survey shows that food intake is embedded in the meal structure, which varies according to the stages of the life cycle, from childhood to adulthood and then to old age ${ }^{4}$. The place of meat in the lives of French households also varies according to the organisation of households, depending on whether they are single or in a couple, with or without children, or in a single-parent situation. It varies according to the place of the meals during the week or during the weekend, in the morning or in the evening and according to whether they are informal, formal or festive (Moulin 1989). Formal occasions promote meat consumption.

The diversity of meal structures is also sensitive to the effects of income and lifestyle. Low incomes limit meat consumption. This structure represents the relatively stable framework for observing the emergence of new eating behaviours.

For some of our interviewees, meat is consumed almost systematically at lunch. The image of meat is then associated with a source of vital energy, which "nourishes the body all day long". Therefore, the absence of meat, for some interviewees, is considered as a "gap": lunch without meat would not be "a real meal".

Meat consumption also varies according to the seasons. In summer, it is associated with grilled meats and barbecues generally cooked by men, even if men's participation in culinary practices seems to remain marginal in our survey. Other surveys show that men are more involved in DIY and gardening. In winter, long-cooked meats are prepared. Boiled and grilled forms of meat often mark the rhythm of winter and summer.

Meat consumption can be linked to ethnic and religious affiliation. Indeed, for some interviewees, the fact that particular foods are forbidden can disrupt protein intake. This is the case for the children of a Muslim woman who do not eat meat in their school canteen because it is not halal. In the evening, their mother buys halal meat to compensate for the lack of meat at lunch. More "exceptional" family celebrations, such as Christmas or Easter for Christians, Kippur or Pesach (Passover) for Jews, or Ramadan or Eid El Kebir for Muslims, are particularly revealing of traditions and the will, or lack of will, to maintain them, through a particular dietary ritual. Lamb meat is central for the latter.

On weekdays, time constraints are severe, between the return from work around 6 p.m., meal preparation, homework follow-up, bathing, dinner and bedtime for children, for those who have children, around 8 p.m. / 8:30 p.m. It all starts again in the morning between 7 a.m. and 8:30 a.m., with getting up, breakfast and going to school. The weekend is less stressful. Women, or men, who like to cook have more time than during the week. It therefore represents an opportunity to eat more meat because they have more time to cook.

For families who consume meat, the weekend is the time to prepare dishes that require a long cooking time, such as the "pot-au-feu" (stew) made of boiled meat and vegetables. For some, Sunday is "chicken day". The weekend may also be an opportunity to receive your family, and, depending on the culture, to receive them by preparing more "typical" dishes. This is what one interviewee does when she prepares Haitian dishes, made from meat or fish, which she considers "mandatory" on pain of risking conflict with her family, which is very attached to traditions.

Whether during the day, at weekends or during holiday meals, meat consumption is embedded in a set of social norms and symbolic signs that act as barriers to the transition to more economical meat consumption. Today, meat is still one of the great signs of a festive meal. For some French people, an ordinary meal without meat is not considered a "real" meal. The presence of meat means the social or emotional importance you want to show to your family or friends. It symbolises the celebration in the great occasions of staging the social bond. Not preparing meat can be a risk in terms of identity, and in terms of self-image. You can be seen as a miser, as someone who does not respect the norms of the family, 
who denies his cultural origins or his territory, and therefore does not fit into the game of gift and social counter-gift, of which meat is a strong symbol.

The social uses of meat ultimately act as constraints against more economical consumption of meat products and the energy costs associated with cooking them.

The strength of these constraints does not mean that they cannot evolve. It means that limiting meat consumption is a transgressive practice and therefore this change in behaviour is not self-evident. Vegan practices, whether strict or flexible, symbolise this transgressive behaviour. For the time being, this is a rather young practice, even an adolescent one. It remains an extremely small minority in France. Vegan people may represent the "pioneers" on the innovation development curve. They have "militant" or "entrepreneurial" behaviours. They are ready to transgress, which requires a high expenditure of human energy in order to accept the human and emotional cost associated with it. Not being in compliance with your home group is a risk to maintain social cohesion. Not all actors are willing to take this risk unless another stronger constraint, particularly in terms of "cognitive dissonance", leads them to limit their meat consumption on festive occasions. The constraint of purchasing power often leads to ecologically virtuous behaviour due to lack of income.

The survey shows that there are opposing forces in favour of more economical consumption. For single interviewees, when dinner is taken alone, it is not very elaborate. It is a matter of making a quick meal, in order to devote as little time as possible to it. Loneliness does not encourage the production of dishes which take a long time to prepare. Meat will therefore not systematically be cooked or consumed. Being alone seems to be a factor in favour of more economical meat consumption and therefore goes in this direction of the energy transition.

At the macrosocial level, there is a double trend of growth and decline in meat consumption. The rise of the world's upper middle class around the 2000s was accompanied by a very strong increase in meat consumption: beef in most countries and pork in China. In emerging countries, eating meat is a sign of an improvement in their standard of living. This was observed in France between 1950 and 1990, where meat consumption rose from $44 \mathrm{~kg}$ per person to $99 \mathrm{~kg}$ (ADEME 2014). This corresponds to the time when the French middle class entered the mass consumption market.

On the other hand, since 1990, meat consumption has been decreasing in France. This decrease can be attributed to three factors: the 1986 mad cow crisis, the fall in the purchasing power of the lower middle class between 1992 and 1997, then again from the early 2000s, heralding the yellow vest crisis in 2018 in France, and finally the ageing of the population, which acts against meat diets. An article in French in Les Échos of 11 July 2017, based on an FAO report, shows that meat consumption will tend to stabilise for emerging countries in the coming years, as in France from the 1990s onwards. These macrosocial elements point in the direction of a decrease in meat consumption and therefore sustainable development.

All this means that on a microsocial level, that of the household and family, we can observe practices that favour meat consumption. However, on a macrosocial scale, we are witnessing a stabilisation of this consumption for the BRICs and a decrease for Western European countries such as France. For the time being, it is difficult to weight the explanatory part, which is related to the social norm related to the "real" (microsocial) meal, the change in dietary value given to meat (generational life cycle variable) or the health constraint related to an ageing population (macrosocial), in explaining the evolution of more economical meat consumption. It is this indeterminacy of causes, linked to the effect of situation, which is found at two scales of actors' interplay, the microsocial and the mesosocial, which makes it possible, in this article, to deconstruct the essentialist explanation through domination.

The great advantage of this example is that it relates to a "virtuous" case of behaviour change which suggests that everyone will agree to change his/her behaviour. The gap between possible willingness to change and real change in practice is explained by the existence of material, social and symbolic constraints that affect the daily lives of social actors. This shows that, even in a favourable case of change, the occurrence of change is not self-evident and therefore domination does not explain everything. 


\section{CONCLUSION}

In the context of this public order, the observation of the constraints on changing practices in favour of reducing meat consumption therefore shows that the objective of "disciplining" behaviour in favour of the ecological transition is not easier to achieve than in the case of management and marketing. The change in the scale of observation makes it possible to reveal a causality other than that of the dominance effect that would be caused by a public policy used as "an instrument of social conformation in the face of resistance to change", to use the initial quotation that criticises "applied research", i.e. ROD.

However, by changing the scale of the observation, the dominance effect disappears in favour of the observation of the actors' strategies in interaction with their family, friends or school. Their flexibility varies according to changes in the situation. It is the change in the scale of observation that makes it possible to deconstruct the essentialist dimension of domination in favour of a more constructivist approach that shows that, depending on the focal point of observation chosen, domination is more or less strong, and more or less relevant in order to explain eating behaviours.

Changing the scale of observation or focus on a given scale or survey theme is one of the skills acquired by the practice of Research on Demand (ROD). Whether the request is public or private, the socio-anthropologist does not choose his field. He is therefore subject to a whole series of budget, time and investigation constraints that lead him to be intellectually very mobile and creative. He must constantly enter new fields, possibly in different cultures, and of which he often knows nothing because they are emerging problems ${ }^{5}$. This permanent uncertainty requires him to develop a methodological expertise and a theoretical flexibility that allow him to find his way in unknown territories where his usual reference points are absent. To find his way, he often has to change his scale of observation, because he does not know a priori whether it is an individualistic explanation, or an explanation by domination or by the constraints of the situation that will be the most relevant. By multiplying the number of clients, he also increases his autonomy and thus minimises conflicts of interest.

The resulting transferable knowledge reveals the diversity of possible explanatory models. It therefore limits the risks of mobilising an essentialist approach that refers to a single and almost absolute causality. It leads to the adoption of an agnostic vision because of the very existence of observation scales. It becomes impossible to say that if we do not see a social dimension it does not exist since, depending on the scale, some of the social phenomena appear or disappear.

Domination is visible at the macrosocial level. It is not very visible at the scales of actors' interplay. It can "reappear" on the individual observation scale. Observation is therefore discontinuous between observation scales. This is why it is not possible to produce an overall theory. However, each theory remains valid according to the scale of observation from which it was constructed. Paradoxically, it is its generalisation to other scales of observation that makes it false. This is why the transferable knowledge produced by the practice of ROD leads to an epistemology which is inclusive (each theory has its relevance, but at a given scale) and cumulative (each new terrain brings a different perspective according to its scale of observation) but without being fusional since no theory can be all-encompassing.

Meat consumption is a good example of this field of contradictory forces that arise from the effects of social classes, generation or life cycle effects and therefore from possible dominance effects at the macrosocial level, but at the same time from situation effects that arise at the microsocial level. This conflicting field of forces explains why the mere explanation of change through domination cannot reflect the diverse nature of change.

The constraint of changing fields that weighs on ROD leads socio-anthropologists to take into account several levels of explanation. The domination-based approaches of Pierre Bourdieu and Michel Foucault remain relevant, as do the individual-centred approaches of Raymond Boudon, François de Singly and Gerald Bronner, but, each at its own observation scale. None of them provides an overall answer, which makes it possible to avoid a form of essentialism close to a form of determinism, which is always difficult to accept in the social sciences and humanities, where contingency and serendipity seem to hold an important place. 
It is by seeking to solve puzzles that focus on human behaviour at the request of a wide range of clients that ROD has acquired mobile, constructivist, cumulative and inclusive knowledge that is not fusional. This diversification of empirical research is probably one of the richest avenues for cooperation between parts of academic research, even if it remains focused on the theoretical competition between peers and militant denunciation, and empirical and inductive ROD. This amounts to the search for what is true being placed at the heart of empirical socio-anthropological practices.

\section{ENDNOTES}

1. My last survey in 2018 on the functioning of a large organisation was carried out for an international company in France, the United States, China and Brazil. It covered 5 factories, from the various departments to the CEOs. In particular, we understood the strength of China's price constraint on the world market. China itself is under pressure to limit its unemployment, among other things.

2. Cf. Lewin 1947 in his research in on the social conditions of increase in the consumption of meat. In this article he describes the decision as a social process made of steps., as an "itinerary" (Desjeux 2018, 123-132; 147-160).

3. The term culture has a social sense in the United States more often than it does in Britain and France, cf. Tett 2015: "In the United States [carrying out research on the marriage practices of the Tajik] is known as cultural anthropology. In the U.K. it is known as social anthropology"; Cuche 2010.

4. At the microsocial level, we focussed on two strategic locations in the domestic space in terms of energy consumption, the kitchen, for meat, and the living room, or lounge, for ICT, with computers, tablets, fixed, mobile and "smart" phones, and televisions. The interviews and observations carried out by Estelle Galateau cover 25 people aged 25 to 56 , nearly $50 \%$ of whom are young people. In this article we only present the case of meat.

5. The footnotes are there to illustrate some of the diversity of the fields we have worked in, in particular Desjeux 2018, a publication which has 26 chapters and includes a whole series of surveys on organisations in France, witchcraft in Africa, consumption in China and the rise of the global middle class

\section{REFERENCES}

Becker, H. S. (2017). Evidence. Chicago: University of Chicago Press.

Bentham, J. (1780). Introduction to the Principles of Morals and Legislation. London: T. Payne.

Boltanski, L., \& Chiapello, E. (2005). The New Spirit of Capitalism. London: Verso. First published in 1999 as Le nouvel esprit du capitalisme, Paris: Gallimard.

Boltanski, L. (2014). Mysteries and Conspiracies. Cambridge: Polity. First published as Boltanski, Luc, 2012, Enigmes et complots. Paris: Gallimard.

Clastres, P. (1977). Society against the State. New York: Urizen Books. First published as Clastres, Pierre. 1972. La Société contre 1'Etat. Paris: Les Editions de Minuit.

Crozier, M. (1964). The Bureaucratic Phenomenon. Chicago: The University of Chicago Press. Originally published as Crozier, Michel. 1963. Le phénomène bureaucratique. Paris: Editions Le Seuil.

Cuche, D. (2010). La notion de culture dans les sciences sociales. Paris: La Découverte.

Desjeux, D. (1980). Le Congo est-il situationniste? 20 ans d'histoire politique. Retrieved from http://www.argonautes.fr/1980-d-desjeux-le-congo-est-il-situationniste-20-ans-dhistoire-politique/

Desjeux, D. (ed.). (2002). Alimentations contemporaines. Paris: L'Harmattan.

Desjeux, D. (2013). Le marketing entre cadrage, consommateurs acteurs et nouvelle émergence sociétale, in: Patrick Bourgne, 2013, Marketing : remède ou poison? Les effets du marketing dans une société en crise. Caen: Editions EMS.

Desjeux, D. (2014). Professional anthropology and training in France. In Denny, Ritta and Patricia Sunderland (eds.), Handbook of Anthropology in Business. Walnut Creek, CA: Left Coast Press. 
Desjeux, D. (2015). Enquête anthropologique et innovation. Retrieved from http://www.argonautes.fr/wp-content/uploads/2015/03/2015-03-ENS-CHIMIE-INNOVATIONMETHODE.pptx

Desjeux, D. (2018). The anthropological perspective of the world: the inductive method illustrated. Brussels: Peter Lang S.A.

Desjeux, D., Galateau, E. F., \& Barbier, C. (2018). (Dé) penser la consommation et économiser l'énergie: une tension entre confort et ascèse. Le cas de la consommation de viande et des usages des TIC comme analyseurs de la consommation d'énergie. In Philippe Moati (ed.), 2018, (De) penser la consommation. Peut-il y avoir une bonne consommation? Caen: Edition EMS.

Desjeux, D. (2019). An anthropological deciphering of the yellow vests in France. Retrieved from http://www.argonautes.fr/2019-january-to-march-the-yellow-vests-in-france/

Foucault, M. (1975). Surveiller et punir. Paris: Gallimard.

Goffman, E. (1961). Asylums: Essays on the social situation of mental patients and other inmates. New York: Anchor Books.

Gouldner, A. W. (1955). Patterns of Industrial Bureaucracy. New York: The Free Press.

Graeber, D. (2015). The Utopia of Rules. New York: Melville House.

Hughes, E. (1962). Good People and Dirty Work. Social Problems, 10(1), 3-11.

Husetowski, C. (2019). Les "transféreurs», ces écolos qui imposent leurs pratiques au boulot. Retrieved from https://gbrisepierre.fr/article-sur-les-transfereurs-dans-slate-korii-juillet-2019/

Jerphagnon, L. (2007). Laudator temporis acti: C'était mieux avant. Paris: Editions Tallandier

Lewin, K. (1947). Group Decision and Social Change. In: Newcomb, T. and Hartley, E. (eds.). Readings in Social Psychology, 197-211. New York: Holt, Rinehart \& Winston.

Milgram, S. (1974). Obedience to Authority: An Experimental View. New York: Harper \& Row

Moulin, L. (1989). Les liturgies de la table. In Albin, Michel, Isabelle Garabuau-Moussaoui, Élise Palomares, and Dominique Desjeux, (eds.). 2002. Alimentations contemporaines. Paris: L'Harmattan.

Sahlins, M. (1972). Stone Age Economics. New York: Routledge.

Scott, J. C. (2017). Against the Grain: A Deep History of the Earliest States. New Haven: Yale University Press.

Tett, G. (2015). The Silo Effect: The Peril of Expertise and the Promise of Breaking Down Barriers. New York: Simon \& Schuster Paperbacks.

Younge, G. (2019). Britain is run by a self-serving clique. That's why it's in crisis. The Guardian. Retrieved July 5, 2019, from https://www.theguardian.com/commentisfree/2019/jul/05/britain-run-self-serving-clique-crisis-na rrow-section?fbclid=IwAR1dWyO5CEVGJAz2BLk0R1wuv-q7aoYu0wzaDAxzGcP5kLTLyM WOcHeObmE 